\title{
Immediate postpartum intrauterine contraceptive device insertions in caesarean and vaginal deliveries: a comparative study
}

\author{
Ritu Goyal, Mini Bedi*
}

Department of Obstetrics and Gynecology, Adesh Institute of Medical Sciences and Research, Bathinda, Punjab, India

Received: 24 July 2020

Revised: 07 September 2020

Accepted: 09 September 2020

\author{
*Correspondence: \\ Dr. Mini Bedi, \\ E-mail: dr.h.sandhu@gmail.com
}

Copyright: (c) the author(s), publisher and licensee Medip Academy. This is an open-access article distributed under the terms of the Creative Commons Attribution Non-Commercial License, which permits unrestricted non-commercial use, distribution, and reproduction in any medium, provided the original work is properly cited.

\begin{abstract}
Background: Post-partum family planning is prevention of unintended and closely spaced pregnancies during first 12 months following childbirth. Postpartum IUCD is the best method of all as it is the safest, most effective, has no effect on breast feeding, reliable and with minimum complications.

Methods: The cross-sectional study was conducted in AIMSR Bathinda on 400 postpartum patients. It was a prospective, observational study of women who received PPIUCD in our region.

Results: Out of total 400, 58\% had normal vaginal delivery and 42\% had cesarean section. PPIUCD was done in all cases after applying exclusion criteria and the females were called for follow up. 53\% cases who had cesarean and $47 \%$ of normal vaginal delivery turned up for follow up. Acceptance is more in multipara $(20.7 \%)$ than in primi patients (13.7\%). Almost $90 \%$ patients had good continuation rate. There were few problems faced by patients like irregular bleeding for first few months, pain lower abdomen, leucorrhea etc. which were removed by good counseling and some treatment like NSAIDs for bleeding.

Conclusions: The acceptance of PPIUCD was high in present study in both types of females delivered by normal vaginal delivery or post LSCS but with good counseling efforts. It was safe and effective and had high retention rate when done at good timing by trained service provider that is within 10 minutes of placental delivery. So the need of time is creating awareness of public towards it and removing fear from minds, breaking taboos and myths.
\end{abstract}

Keywords: Lower segment caesarean sections, Non-steroidal anti-inflammatory drugs, Postpartum intrauterine contraceptive device

\section{INTRODUCTION}

Post-partum family planning is prevention of unintended and closely spaced pregnancies during first 12 months following childbirth. ${ }^{1}$ Family planning can avert nearly one-third of maternal deaths and $10 \%$ of child mortality when couples space their pregnancies about two year's apart. $^{2}$ Short intervals between births are linked with higher maternal and child mortality and morbidity. ${ }^{3}$ Postpartum women need a range of effective contraceptive methods to be able to prevent an unplanned pregnancy, within a short interval. ${ }^{2,3}$ Early resumption of sexual activity along with unpredictable ovulation leads to many unwanted pregnancies in first postpartum year.
In addition, women from distant areas do not return even for postpartum checkups leaving aside contraception resulting in early unwanted pregnancies. In India, the 2015-2016 National Family Health Survey (NFHS) reported that $58 \%$ of births were spaced less than three years. $^{4}$ Intrauterine contraceptive device to prevent pregnancy is among the oldest method of contraception. IUCD has established itself as an effective, reliable and safe method of contraception with minimum complications. It can be safely used in all breastfeeding females. ${ }^{5}$ But its acceptance remains low. According to the World Health Organization Medical Eligibility Criteria, an IUCD can be inserted within 48 hours postpartum, referred to here as a postpartum IUCD 
(PPIUCD), or after four weeks following a birth. ${ }^{6}$ Increasing number of women in India are delivering in hospitals after introduction of JSY and JSSK. Since the inception of JSY, facility-based births in the public sector have increased from 700,000 in 2005 to more than 11 million in $2012 .^{7}$ It allows opportunity for the state to provide PPIUD in a big way. But it needs good counselling. This is particularly important for the females who have limited access to medical care. Most of these beneficiaries attend government setups or setups where JSY benefit is given.

WHO has revised the use of IUCD from the $6^{\text {th }}$ week postpartum to within 10 minutes of delivery to 48 hours of delivery. ${ }^{8}$ It is considered as one of the safe and effective method of contraception? It can be inserted safely in all breast-feeding women, any time during first 48 hrs after delivery, 6 weeks postpartum or post abortal. But it is still not so popular although government has started giving incentives to health workers for motivation of females. In India $10.2 \%$ of women use temporary contraceptive method and that of IUCD is just $1.8 \%$ as contraceptive method. ${ }^{9}$ Due to lack of awareness, fear in mind about usage of contraception, social pressure, taboos and myths and sometimes non availability of accessible family planning services make the females vulnerable to unwanted pregnancies. One more reason could be that family planning services in India are skewed towards sterilization particularly female sterilization. Use of a modern method among married women in India is $49 \%$ and female sterilization accounts for $77 \%$ of this group. With increasing numbers of women electing to give birth in health institutions, the Government of India decided to strengthen PPFP and to introduce PPIUCD services in a phased manner. Previously, concerns about the PPIUCD were high expulsion rates about 9-13\%.10,11 However, lower expulsion rates have been reported more recently with improvements in insertion technique. ${ }^{12,13}$

\section{Objectives}

PPIUCDs are still emerging as a relatively new contraception choice in India. While follow-up data on complications with PPIUCD insertions are mostly available from international sources, it was important to generate country-based evidence on the post-insertion outcomes after the introduction of PPIUCD program. Additionally, to gain information related to the demographic profile of women who accept PPIUCDs, their satisfaction with this method of contraception, and complications with the IUCD. Therefore, we conducted a prospective and observational study of women who received PPIUCD in our region.

\section{METHODS}

A cross sectional study was conducted in AIMSR Bathinda on 400 postpartum patients from Feburary 2018 to Feburary 2020.

\section{Inclusion criteria}

All antenatal patients admitted for delivery to our hospital were counseled for PPIUCD. Informed consent was taken from those who opted for it after briefing them about mechanism of action, effectiveness, risks etc. The following criteria were chosen: $18-40$ years old; 36-40 weeks gestational age; $\mathrm{Hb}>8 \mathrm{gm} / \mathrm{dl}$; desirous of contraception after delivery.

\section{Exclusion criteria}

Fever during labor and delivery; Any uterine anomalies like bicornuate, septate, uterine myoma; manual removal of placenta; PPH cases; patients with active genital infections; PPROM; severe anemia; and heart disease.

\section{Procedure}

The IUCD used was CuT-380A. This was placed in uterine fundus with the help of long and curved forceps without lock (Kelly's placental forceps) for vaginal insertions, within 10 minutes of removal of placenta. During caesarean section ring forceps were used to place the IUCD in fundus of uterus through the lower segment incision which was closed subsequently as routine. The IUCD strings were not trimmed in both types of insertions and left in uterine cavity. Active management of third stage of labour was performed as routine. All PPIUCD insertions were done by doctors who had been trained for this purpose. Post insertion counselling was done and women were advised to follow-up for examination at our centre after 6 week and so on. The primary outcome measures were clinical outcomes in terms of efficacy means expulsions, pregnancy, discontinuation and safety in terms of complications like perforation, irregular vaginal bleeding, infection, discharge $\mathrm{P} / \mathrm{V}$. These outcomes were compared for vaginal and caesarean PPIUCD insertions. Statistical analysis was carried out using SPSS version. Chi square tests were used for comparison in different categorical variables and results were considered statistically significant.

\section{RESULTS}

After applying the exclusion criteria, 400 women were recruited in study.

Table 1: number of vaginal deliveries and caesarean sections.

\begin{tabular}{|lll|}
\hline Mode of delivery & No. of cases & Percentage \\
\hline Vaginal delivery & $232 / 400$ & $58 \%$ \\
\hline Caesarean section & $168 / 400$ & $42 \%$ \\
\hline
\end{tabular}

Out of 400, 58\% had spontaneous vaginal delivery and $42 \%$ had caesarean section Mean gestation age at the time of delivery was 38.5 weeks with SD of 1.45 . 
Table 2: Demographics of PPIUCD.

\begin{tabular}{|lll|}
\hline Characteristic & $\begin{array}{l}\text { Vaginal } \\
\text { delivery }\end{array}$ & $\begin{array}{l}\text { Caesarean } \\
\text { section }\end{array}$ \\
\hline Age (years) & 36 & 12 \\
\hline$<20$ & 72 & 56 \\
\hline $20-29$ & 102 & 72 \\
\hline $30-39$ & 22 & 28 \\
\hline$>40$ & & \\
\hline Parity & 72 & 62 \\
\hline 1 & 86 & 88 \\
\hline 2 & 74 & 18 \\
\hline$>3$ & & \\
\hline Education & 15 & 9 \\
\hline Illiterate & 120 & 92 \\
\hline Primary education & 97 & 74 \\
\hline Higher education & & \\
\hline Occupation & 148 & 67 \\
\hline House wife & 62 & 58 \\
\hline Unskilled worker & 22 & 43 \\
\hline Skilled worker & &
\end{tabular}

In this study majority of women $94 \%$ had at least primary education. Acceptance is more in multipara (20.73\%) than primi patients $(13.7 \%)$.

Table 3: Follow ups taken by cases.

\begin{tabular}{|lll|}
\hline Follow ups & Total (192) & Percentage (48\%) \\
\hline $\begin{array}{l}\text { Caesarean } \\
\text { sections }\end{array}$ & 102 & $53.12 \%$ \\
\hline Vaginal delivery & 90 & $46.8 \%$ \\
\hline
\end{tabular}

All women were followed for short and long term complications. Follow up was taken by $48 \%$ of total insertions. Out of these follow up cases $53 \%$ were of Csection and $47 \%$ were those who had normal vaginal delivery but there was no significant difference in follow up visits in both types. There was no significant difference in long term complications and satisfaction rates in both the groups.

Table 4: problems faced by females at 6 weeks follow up.

\begin{tabular}{|lll|}
\hline Problems faced & $\begin{array}{l}\text { Vaginal } \\
\text { delivery }\end{array}$ & $\begin{array}{l}\text { Caesarean } \\
\text { section }\end{array}$ \\
\hline Request for removal (15/192) & $5.7 \%(11)$ & $2 \%(4)$ \\
\hline $\begin{array}{l}\text { Vaginal discharge and } \\
\text { infections (28/192) }\end{array}$ & $9.3 \%(18)$ & $5.2 \%(10)$ \\
\hline Irregular bleeding (16/192) & $4.7 \%(9)$ & $3.6 \%(7)$ \\
\hline Secondary PPH (6/192) & $1.5 \%(3)$ & $1.5 \%(3)$ \\
\hline Infections (8/192) & $2.6 \%(5)$ & $1.5 \%(3)$ \\
\hline
\end{tabular}

Follow up was done at 6 weeks, 6 months and then yearly for three years to see satisfaction and success rate. At 6 weeks postpartum $7.8 \%$ requested removal due to dissatisfaction and abdominal discomfort out of which
$5.7 \%$ were of vaginal delivery and $2 \%$ who had Csection. $14.58 \%$ women reported vaginal discharge which was more in cases who had vaginal delivery. Most of cases had normal leucorrhoea except three who had bacterial vaginosis. Irregular bleeding was seen in $8.3 \%$ cases out of them $4.7 \%$ had NVD and $3.6 \%$ had Csection. Secondary PPH in $3.1 \%$ cases with almost equal no of vaginal delivery and $\mathrm{C}$-section patients. Vaginal infections were reported by $4.1 \%$ of cases with $2.6 \%$ of vaginal delivery and $1.5 \%$ of $\mathrm{C}$-section. But there was no significant statistical difference in two groups in rates of irregular bleeding or secondary $\mathrm{PPH}$.

Table 5: Efficacy of PPIUCD.

\begin{tabular}{|llll|}
\hline $\begin{array}{l}\text { Mode of } \\
\text { delivery }\end{array}$ & $\begin{array}{l}\text { Expulsions } \\
(21 / 192)\end{array}$ & $\begin{array}{l}\text { Displaced } \\
(2 / 192)\end{array}$ & $\begin{array}{l}\text { Perforation } \\
(0 / 192)\end{array}$ \\
\hline $\begin{array}{l}\text { Vaginal } \\
\text { delivery }\end{array}$ & $8.3 \%(16)$ & Nil & Nil \\
\hline $\begin{array}{l}\text { Caesarean } \\
\text { section }\end{array}$ & $2.6 \%(5)$ & $1.04 \%(2)$ & Nil \\
\hline
\end{tabular}

PPIUCD was spontaneously expelled in $8.3 \%$ in postdelivery patients but was $2.6 \%$ in patients who had got it inserted it after caesarean section. It was displaced in $1.04 \%$ cases of only $\mathrm{C}$-section but there was no reported case of uterine perforation.

On subsequent visits $2.5 \%$ requested removal due to menstrual irregularities, sexual discomfort and abdominal cramps. Highest satisfaction rate was observed in multipara between the ages of 20-25 years. Satisfaction rate was $96 \%$ at the time of insertion, $94 \%$ on subsequent visits and overall $95 \%$.

Regarding knowledge about PPIUCD only 39\% (156 1400) had heard of it and $22 \%$ were aware of it in detail. High success rate was observed in those females who were counselled thoroughly in ante-partum and intrapartum. It was about $65 \%$ and $45 \%$ in those who are only counselled in ante-natal period, $36 \%$ in those where intrapartum counselling is done and $19 \%$ of those where it was done immediate postpartum.

\section{DISCUSSION}

The modern IUCD is highly effective, safe, private, long acting coitus independent and rapidly reversible method of contraception with fewer side effects. The postpartum period is potentially an ideal time to begin contraception as women are strongly motivated to do so this time which is convenient for health care provider and the patient. Also, mid discomfort and any bleeding related to insertion is masked by post-delivery symptoms. Many women find it very convenient because it requires little attention once inserted.

In this study majority of women $94 \%$ had at least primary education as compared to study by Mishra that had $95.98 \%$ at least primary educated clients. ${ }^{5}$ Acceptance 
was less in those with no formal education or with higher education. This is similar to study done by Scafwat et al where women with no formal education had acceptance of $9.4 \%$ while those with formal education had $19.4 \% .{ }^{14}$ Acceptance was more in multipara (20.73\%) than primipara $(13.7 \%)$ that is similar to study by Grimes et al that also showed more acceptance in multipara. ${ }^{15}$

Women undergoing caesarean section accept PPIUCD more readily probably because of fear of risk of conception post surgery. Even follow up done was more by patients who had C-section may be because of fear of complications. Shukla et al reported follow up of $78.7 \%$ in a prospective longitudinal study. ${ }^{16}$ While a study done by Hooda et al showed scheduled follow up by only $65.2 \%$ of cases. ${ }^{17}$ In our study although all females undergoing PPIUCD insertion are counselled and advised for follow up but only approximately half of them turn up may be because a large proportion out of them are from rural areas and they prefer follow up at nearest possible health centre rather than coming to tertiary care centre.

There was no reported case of perforation in our study even studies from literature don't show uterine perforation.

In females with vaginal discharge, most of them had normal leucorrhoea. Some patients are more apprehensive regarding discharge because they had undergone a surgical procedure. A multicentric follow up study from India reported an overall infection rate of $4.5 \%$ among PPIUCD insertions. ${ }^{18}$ Welvoic et al compared infection rates among women with postplacental IUD and women without IUD and found no difference. ${ }^{19}$ Few studies show no incidence of infection after PPIUCD.

The symptom of irregular bleeding was treated symptomatically with NSAIDs, tranexemic acid and hematanics. Gupta et al observed bleeding in $4.3 \%$ PPIUCD cases with cut $380 \mathrm{~A} .{ }^{20}$ Shukla et al observed higher incidence of menorrhagia with use of cut 200 in postpartum females. ${ }^{16}$

Husband and other family pressure for IUCD removal was also a significant reason $23.5 \%$ for removal next to bleeding. $8 \%$ had lost strings at 6 weeks follow up out of which in $5 \%$ strings were found at cervical canal but in rest of cases confirmation that IUCD was in situ was done by USG. These cases requested removal but were counselled adequately to continue with PPIUCD.

IUCD expulsion was observed in few cases may be because of right time of insertion that is within 10 minutes of delivery of placenta. A study by Pulwasha et al showed expulsion rates of $4.2 \%$ whereas study by Celen et al reported $11.3 \%$ cumulative expulsion rate for postpartum insertion of CuT 300B. ${ }^{21,22}$ Kittur et al study showed similar results using similar technique and timing (that is within $10 \mathrm{~min}$ of placental delivery) that has fewer expulsions $(5.23 \%)$ as in present study. ${ }^{23}$ The expulsion were higher in females with post vaginal delivery IUCD insertion in our study which is comparable to study done by Gupta et al. ${ }^{20}$ Lette et al also showed similar results. ${ }^{24}$ The timing of insertion, counselling and provider training are important factors for IUCD insertion success in postpartum as per UNPOPIN report. ${ }^{25}$

Pregnancy rate within 6months of expulsion and removal of IUCD is about $17 \%$ as compared to study by Mishra et al where it is $14.63 \%$ which shows poor contraceptive practice and acceptance of any other method. ${ }^{5}$

But still even after counting discontinuation and expulsion the continuation rate was $90 \%$.

So PPIUCD is an opportunity not to be missed and delivery is the best time when a woman can avail it when there is uncertainty about return of her for the same. It is easy to insert, cost effective, protect from unwanted pregnancies and abortions and safe in breast feeding females.

\section{CONCLUSION}

The acceptance of PPIUCD was high in present study in both types of females delivered by normal vaginal delivery or post LSCS but with good counselling efforts. It was safe and effective and had high retention rate when done at good timing by trained service provider that is within 10 minutes of placental delivery. So the need of time is creating awareness of public towards it and removing fear from minds, breaking taboos and myths. Moreover when government is giving cash incentives to provider and motivator it should bring a major change in family planning data which is need of hour in case of developing country like India.

\section{Funding: No funding sources Conflict of interest: None declared \\ Ethical approval: The study was approved by the Institutional Ethics Committee}

\section{REFERENCES}

1. Novodani KT, Foneska P, Goonewardena CS. Postpartum family planning: missed oppurtunities across the continuum of care. Ceylon Med J. 2017;2:87-91.

2. Cleland J, Bernstein S, Ezeh A, Faundes A, Glasier A, Innis J. Family planning: the unfinished agenda. Lancet. 2006;368:1810-27.

3. Rutstein SO. Effects of preceding birth intervals on neonatal, infant and under-five years mortality and nutritional status in developing countries: evidence from the demographic and health surveys. International J Gynecol Obstet. 2005;89:S7-24.

4. International Institute for Population Sciences (IIPS) and Macro International: National Family Health 
Survey (NFHS-3). 2015-16. Available at: https://dhsprogram.com/pubs/pdf/FR339/FR339.pdf.

5. Mishra S. Evaluation of safety, efficacy and expulsion of post-placental insertion of intracesarean insertion of intauterine contraceptive device (PPIUCD). J Obstet Gynecol India. 2014;64(5):33743.

6. World Health Organization: Medical Eligibility Criteria for Contraceptive Use. 4th edition. Geneva: World Health Organization; 2010. Available at: https://www.who.int/reproductivehealth/publications /family_planning/9789241563888/en/.

7. Government of India: All India Summary of National Rural Health Mission Program. 2012. In Available at: http://www.nrhm.gov.in/monitoring/progress-ofnrhm.html. Accessed on 8 March 2013.

8. WHO. Medical Eligibility Criteria for Contraceptive use. 5th ed. Geneva WHO; 2015. Available from: https://www.who.int/reproductivehealth/publications /family_planning/MEC-5/en/.

9. International Institute for Population Sciences (IIPS) and Macro International. National Family Health Survey (NFHS-3) India. 2005-2006. Key Findings. Mumbai, IIPS, 2007. Available at: http://www.measuredhs.com/pubs/pdf/SR128/SR128 .pdf. Accessed on 14 March 2013.

10. Tatum HJ, Beltran RS, Ramos R, Van Kets H, Sivin I, Schmidt FH. Immediate postplacental insertion of GYNE-T 380 and GYNE-T 380 postpartum intrauterine contraceptive devices: randomized study. Am J Obstet Gynecol. 1996;175:1231-5.

11. Celen S, Möröy P, Sucak A, Aktulay A, Danisman N. Clinical outcomes of early postplacental insertion of intrauterine contraceptive devices. Contraception. 2004;69:279-82.

12. Araujo VB, Ortiz L, Smith J. Postpartum IUD in Paraguay: a case series of 3000 cases. Contraception. 2012;86:173-86.

13. Blumenthal P, Shiliya N, Neukom J, Chilambwe J, Vwalika B, Prager B, et al. Expulsion rates and satisfaction levels among immediate postpartum IUD users in peri-urban Lusaka, Zambia. Contraception. 2011;84:320.

14. Mohamed SA, Kamel MA, Shaaban OM, Salem HT. Acceptability for the use of postpartum intrauterine contraceptive devices: Assiut experience. Med Principle Pract. 2003;12(3):170-5.

15. Grimes D, Schulz K, van Vliet H. Immediate postpartum insertion of intrauterine devices: a Cochrane review. Hum Reprod. 2002;17(3):549-54.
16. Shukla M, Qureshi S, Chandrawati. Post-placental intrauterine device insertion- a five year experience at a tertiary care centre in north India. Indian $\mathbf{J}$ Med Res. 2012;136:432-5.

17. Hooda R, Mann S, Nanda S, Gupta A. Immediate postpartum intrauterine contraceptive device insertions in caesarean and vaginal deliveries: a comparative study of follow-up outcomes. Int $\mathrm{J}$ Reprod Med. 2016;2016:1-5.

18. Sood B, Asif R, Charurat E, Das S, Kumar S, McKaig C, et al. Revitalization of postpartum IUCD (PPIUCD) services: experience from India. Contraception. 2012;86(2):184-5.

19. Welkovic JS, Costa F, Faundes A. Post-partum bleeding and infection after post-placental IUD insertion. Contraception. 2001;63(3):155-8.

20. Gupta A, Verma A, Chauhan J. Evaluation of PPIUCD versus interval IUCD (380A) insertion in a teaching hospital of Western UP. Int J Reprod Contracept Obstet Gynecol. 2013;2:204-8.

21. Iftikhar PM, Shaheen N, Arora E. Efficacy and satisfaction rate in postpartum intrauterine contraceptive device insertion: a prospective study. Cureus. 2019;11(9).

22. Çelen S, Sucak A, Yildiz Y, Danis N. Immediate postplacental insertion of an intrauterine contraceptive device during cesarean section. Contraception. 2011;84(3):240-3.

23. Kittur S, Kabadi YM. Enhancing contraceptive usage by post-placental intrauterine contraceptive devices (PPIUCD) insertion with evaluation of safety, efficacy and expulsion. Int $\mathbf{J}$ Reprod Contracept Obstet Gynecol. 2012;1:26-32.

24. Muller ALL, Ramos JGL. Transvaginal ultrasonographic assessment of the expulsion rate of intrauterine devices inserted in the immediate postpartum period: a pilot study. Contraception. 2015;72(3):192-5.

25. United Nations Population Information Network (POPIN) UN Population division. Department of Economic and Social Affairs with support from UN Population Fund. Network Intrauterine devices Family Health International. 1996;16 (2).

Cite this article as: Goyal R, Bedi M. Immediate postpartum intrauterine contraceptive device insertions in caesarean and vaginal deliveries: a comparative study. Int J Reprod Contracept Obstet Gynecol 2020;9:4140-4. 